\title{
Double-quantum filtered heteronuclear correlation spectroscopy under magic angle spinning
}

\author{
Yao-Hung Tseng ${ }^{\mathrm{a}}$, Yi-Ling Tsai ${ }^{\mathrm{a}}$, Tim W.T . Tsai ${ }^{\mathrm{a}}$, Chun-Pin Lin ${ }^{\mathrm{a}, \mathrm{b}}$, Shih-Hao Huang ${ }^{\mathrm{a}, \mathrm{b}}$, \\ Chung-Yuan Mou ${ }^{\mathrm{a}, \mathrm{c}}$, Jerry C.C. Chan ${ }^{\mathrm{a}, *}$ \\ ${ }^{a}$ Department of Chemistry, National Taiwan University, 1, Section 4, Roosevelt Road, Taipei, Taiwan \\ ${ }^{\mathrm{b}}$ Graduate Institute of Clinical Dentistry, National Taiwan University, Taipei \\ ${ }^{c}$ Center of Condensed Matter, National Taiwan University, Taipei, Taiwan
}

Received 30 September 2006; received in revised form 29 December 2006

Available online 8 January 2007

\begin{abstract}
We present a simple experimental method to extract the van Vleck second moment of a multiple-spin system under high-resolution condition. The idea is to incorporate a double-quantum (DQ) filter into the pulse sequence of heteronuclear correlation spectroscopy so that a DQ excitation profile can be obtained by measuring a series of $2 \mathrm{D}$ spectra. The effects of spinning frequency and proton decoupling are demonstrated on the measurements of two model compounds, viz. hydroxyapatite and brushite. Based on the results obtained for the model compounds, the P-31 homonuclear second moment of the apatite component in rat dentin is characterized. The method is generally suited for the study of bone, enamel and dentin.
\end{abstract}

(C) 2007 Elsevier Inc. All rights reserved.

Keywords: Brushite; Calcium phosphate; HAp; NMR; Double-quantum filter; HETCOR; Second moment; Dentin; Teeth

\section{Introduction}

Studies of calcified tissues such as bone and teeth are of important interest to the development of biomaterials. The inorganic phase of tooth enamel, dentin and bone was identified as calcium phosphate with an apatite structure in the 1920s [1]. After decades of efforts, the composition and structure of these biological minerals remain poorly characterized at the molecular level. The major difficulty is that significant structural disorder is commonly found in biological hard tissues and therefore the utility of diffraction techniques is very limited. Because solid-state NMR spectroscopy is well suited to the study of amorphous systems, it is not surprising that ${ }^{31} \mathrm{P}$ NMR has been actively applied to the studies of bone minerals [2-12]. While the analysis of ${ }^{31} \mathrm{P}$ magic-angle spinning (MAS) spectra is severely plagued by the inherent poor resolution usually encountered in bone samples, it has been shown that the

\footnotetext{
${ }^{*}$ Corresponding author. Fax: +886223636359.

E-mail address: chanjcc@ntu.edu.tw (J.C.C. Chan).
}

${ }^{31} \mathrm{P}\left\{{ }^{1} \mathrm{H}\right\}$ heteronuclear correlation (HETCOR) spectroscopy can effectively alleviate the resolution problem $[3,11]$. Recently, it has been demonstrated that the distance distributions of phosphorus species in bone and dental enamel can be well characterized by the van Vleck second moments, which were obtained by measuring the ${ }^{31} \mathrm{P}$ spinecho amplitudes as a function of echo time under static condition [13]. Second moments can provide useful insights concerning the structural arrangement of the spin nuclei even in amorphous systems. For the study of biominerals, it is therefore highly desirable to develop a method to determine the ${ }^{31} \mathrm{P}$ homonuclear second moments $\left(M_{2}^{P-P}\right)$ under MAS.

There are many different techniques developed for the recoupling of homonuclear dipolar interactions under MAS [14-17]. Interesting applications have been demonstrated for ${ }^{31} \mathrm{P}$ multiple-spin systems [18-22]. In particular, Schmedt auf der Günne [20] shows that for a multiple-spin system it is possible to describe the dephasing behavior of the DQ coherences by a fictitious two-spin system, for which the effective dipolar coupling can be calculated as a 
sum of squared dipolar coupling constants of the multiplespin system. Empirically, Raghunathan et al. [21] also found that the dipolar dephasing curve of HAp can be reproduced both by a nine-spin simulation based on the $\mathrm{X}$-ray structure and by a two-spin simulation corresponding to an effective ${ }^{31} \mathrm{P}-{ }^{31} \mathrm{P}$ distance of $3.1 \AA$. Alternatively, the $M_{2}^{P-P}$ data can be estimated by monitoring the variation of a DQ-filtered signal as a function of the excitation time [23-25]. In this work, we show that a ${ }^{31} \mathrm{P}$ double-quantum (DQ) filter can be incorporated to the HETCOR pulse sequence so that one can extract the corresponding $M_{2}^{P-P}$ data of the apatite component in a dentin sample. To assist the data interpretation, $M_{2}^{P-P}$ data were also obtained for two crystalline model compounds, viz. hydroxyapatite (HAp) and brushite.

\section{Experimental methods}

Hydroxyapatite $\left(\mathrm{Ca}_{10}\left(\mathrm{PO}_{4}\right)_{6}(\mathrm{OH})_{2}\right)$ and brushite $(\mathrm{Ca}$ $\mathrm{HPO}_{4} \cdot 2 \mathrm{H}_{2} \mathrm{O}$ ) were used as received (Acros Organics). The dentin sample was taken from the incisor of a Wistar rat (3 weeks old) after removing the enamel by a high-speed dental drill. The sample was washed with saline for three times and then ground into powder form by a Mortar Grinder KM 100 grinder.

All NMR experiments were measured at room temperature and carried out at ${ }^{31} \mathrm{P}$ and ${ }^{1} \mathrm{H}$ frequencies of 121.5 and $300.1 \mathrm{MHz}$, respectively, on a Bruker DSX300 NMR spectrometer equipped with commercial 2.5- and 4-mm probes. The sample was confined to the middle one-third of the rotor volume using Teflon spacers. The variation of MAS frequency was limited to $\pm 3 \mathrm{~Hz}$ using a commercial pneumatic control unit. Chemical shifts were externally referenced to $85 \%$ phosphoric acid and TMS for ${ }^{31} \mathrm{P}$ and ${ }^{1} \mathrm{H}$, respectively.

The ${ }^{31} \mathrm{P}\left\{{ }^{1} \mathrm{H}\right\}$ DQ filtered Lee-Goldburg cross-polarization (CP) heteronuclear correlation spectra were measured at a spin rate of $25 \mathrm{kHz}$. The flip angle of the pulse after the $t_{1}$ evolution is adjusted so that the spin-temperature inversion can be realized by phase alternating the first ${ }^{1} \mathrm{H}$ $\pi / 2$ pulse. During the contact time, the ${ }^{1} \mathrm{H}$ nutation frequency and the resonance offset were set equal to 50 and $35.35 \mathrm{kHz}$, respectively, to fulfill the Lee-Goldburg irradiation condition [26]. The amplitude of the ${ }^{31} \mathrm{P}$ contact pulse was ramped adiabatically $[27,28]$. The ${ }^{31} \mathrm{P}$ DQ filter was prepared based on the so-called HSMAS-DQ technique [29-31]. During the fp-RFDR recoupling periods, the ${ }^{31} \mathrm{P} \pi$ pulses were set to $12 \mu \mathrm{s}\left(\tau_{p} / \tau_{r}=0.3\right)$ [32]. The $\pi$ pulse trains were phase cycled according to the XY-8 scheme [33]. The ${ }^{31} \mathrm{P} \pi / 2$ pulses flanking the fp-RFDR pulse blocks were set to $5 \mu \mathrm{s}$ [29]. The DQ reconversion period was set equal to the excitation period. The tachometer signals for pulse sequence synchronization were filtered with a homebuilt phase-locked loop circuit. The standard four-step phase cycling of the excitation block $(0, \pi / 2, \pi, 3 \pi / 2)$ and receiver phase $(0, \pi, 0, \pi)$ was used to select the DQ coherence [34]. Together with spin-temperature inversion and CYCLOPS [35] our phase cycling has a total of 32 steps. Quadrature detection in the $F_{1}$ dimension was achieved by the hypercomplex approach [34]. Typically, for each $t_{1}$ increment 128 transients were accumulated, and a total of 31 increments were done at steps of $80 \mu$ s. Recycle delay was set to $3 \mathrm{~s}$. The acquisition time for each DQFHETCOR or HETCOR experiment was $7 \mathrm{~h}$. The total experimental time required to generate a DQ excitation profile was $63 \mathrm{~h}$.

\section{Results and discussion}

\subsection{MAS and HETCOR}

Fig. 1 shows the ${ }^{31} \mathrm{P}$ and ${ }^{1} \mathrm{H}$ MAS spectra measured for the dentin sample at a spin rate of $10 \mathrm{kHz}$. Additional experiment shows that the proton decoupling does not help improve the resolution of the ${ }^{31} \mathrm{P}$ MAS spectrum. The fullwidth at half-maximum of the ${ }^{31} \mathrm{P}$ MAS signal is about $600 \mathrm{~Hz}(5 \mathrm{ppm})$, which is comparable to the data measured for the apatite layer formed on the surface of bioactive glasses [24]. This observation is consistent with the notion that the apatite crystals in dentin have random orientation and their size is pretty small [1]. There are two major components in the ${ }^{1} \mathrm{H}$ MAS spectrum. The sharp component at $1.1 \mathrm{ppm}$ is difficult to assign but its shoulder at $0.2 \mathrm{ppm}$ is readily assigned to the hydroxyl group of apatite [36]. The broad peak at $5.5 \mathrm{ppm}$ is attributed to the structural water [36] and the organic matrix of dentin $(20 \mathrm{wt} \%)$ [1]. Further analysis of the MAS spectra is plagued by the poor spectral resolution. As demonstrated previously, the CP-based HETCOR spectroscopy is particularly useful in the study of apatite materials $[3,37]$. To suppress the spin diffusion among the ${ }^{1} \mathrm{H}$ spins during the CP contact time, LG irradiation was applied in the ${ }^{1} \mathrm{H}$ channel. Fig. 2 shows the ${ }^{31} \mathrm{P}\left\{{ }^{1} \mathrm{H}\right\}$ HETCOR spectrum measured at a spin rate of $25 \mathrm{kHz}$, in which there are two components at ${ }^{1} \mathrm{H}$ chemical shifts of 0.2 and $5.5 \mathrm{ppm}$, which are henceforth referred to as the apatite and the amorphous components, respectively. The signals of these spectral components are assigned to the phosphorus species in the apatite domain and the disordered phase which contains substantial amount of structural water [3]. A careful inspection of the HETCOR spectrum reveals that the ${ }^{31} \mathrm{P}$ chemical shifts of the two components are slightly different, showing that there are indeed two different phosphorus species which have different proton environments.

\section{2. $D Q$ excitation profile}

It has been shown that the $M_{2}^{P-P}$ data of ${ }^{31} \mathrm{P}$ multiplespin systems can be estimated by monitoring the variation of a DQ-filtered signal as a function of the excitation time [23-25]. By the pulse sequence shown in Fig. 3, the DQ excitation profiles were measured for $\mathrm{HAp}$ and brushite. There is one phosphorus site (orthophosphate, $\mathrm{PO}_{4}^{3-}$ ) in 

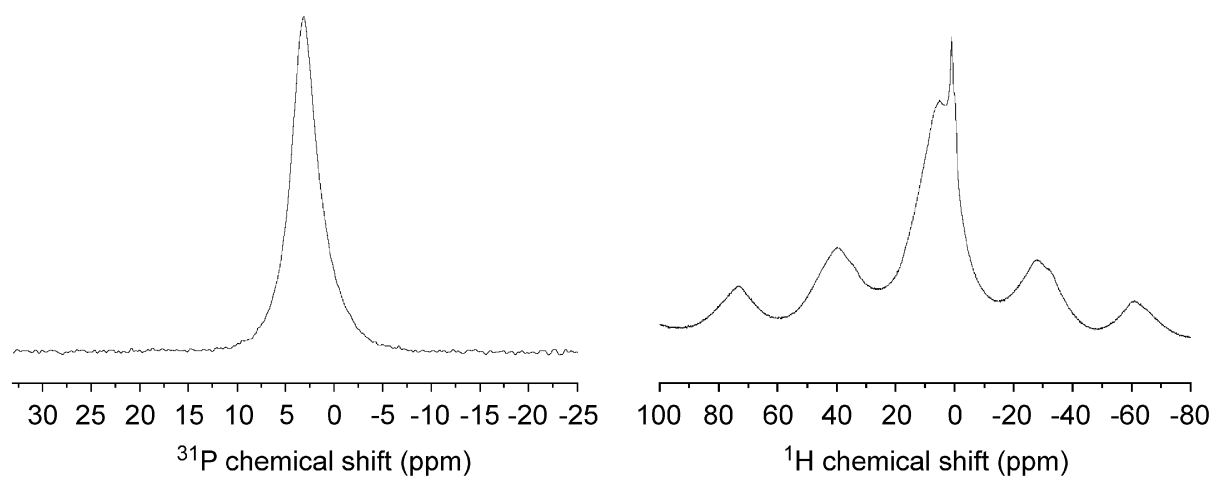

Fig. $1 .{ }^{31} \mathrm{P}$ and ${ }^{1} \mathrm{H}$ MAS spectra of the dentin sample at $10 \mathrm{kHz}$.

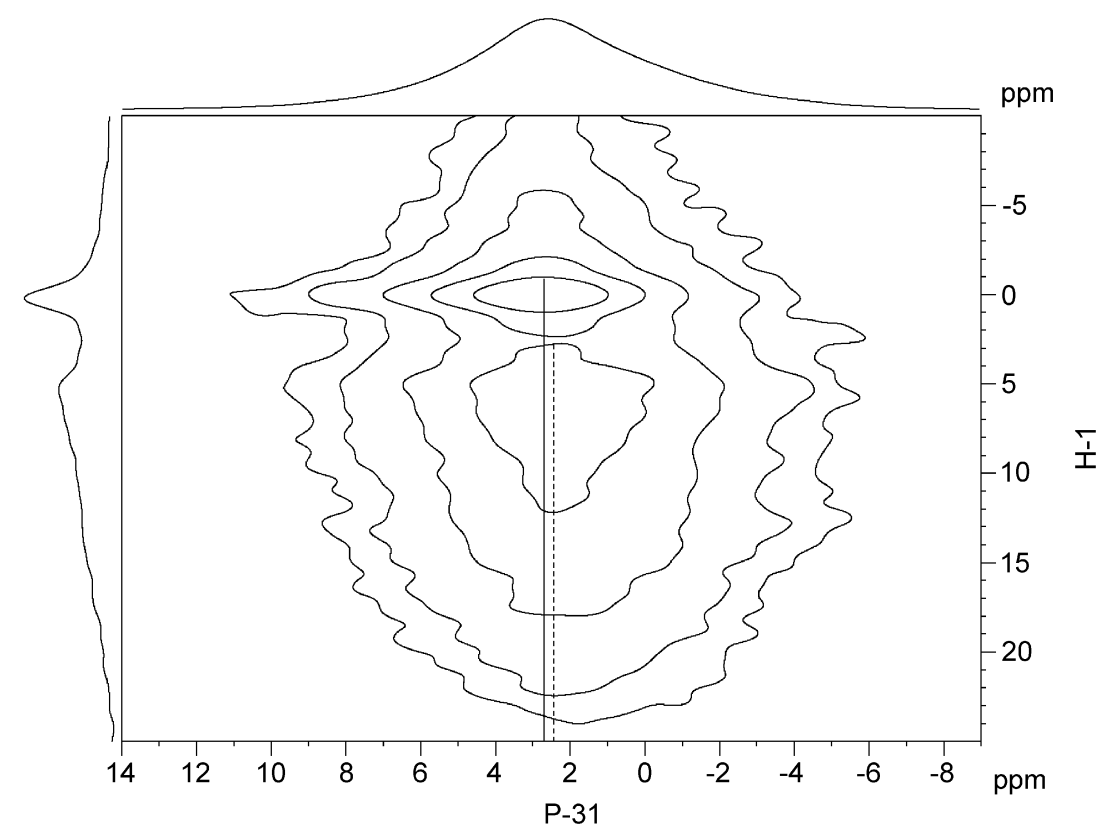

Fig. 2. LG-CP HETCOR spectrum of the dentin sample. The ${ }^{31} \mathrm{P}$ chemical shifts of the two spectral components are slightly different. The peaks at ${ }^{1} \mathrm{H}$ chemical shifts of 0.2 and $5.5 \mathrm{ppm}$ are assigned to the apatite and amorphous components, respectively.

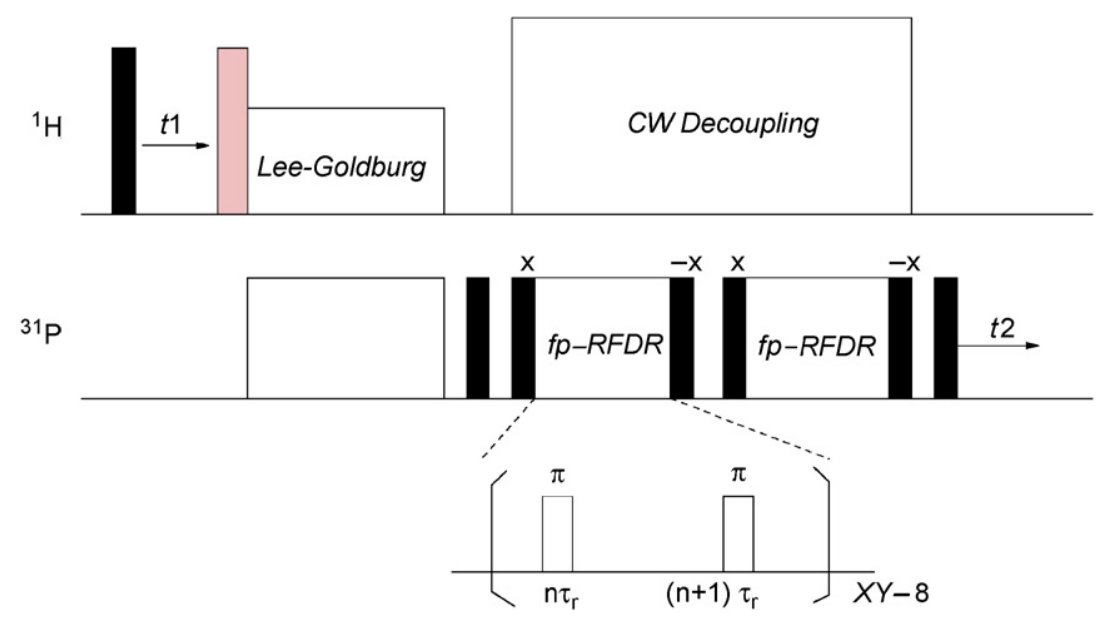

Fig. 3. Pulse sequence designed for the measurements of DQF-HETCOR spectra. The rectangle in gray represents the pulse with a flip angle adjusted to bring the ${ }^{1} \mathrm{H}$ magnetization spin locked along the effective field. The duration of the $\pi$ pulses within the fp-RFDR blocks were set equal to $30 \%$ of the rotor period and the filled rectangles denote $\pi / 2$ pulses of $5 \mu$ s. The $\pi / 2$ pulse following the ${ }^{31} \mathrm{P}$ spin-locking pulse serves to bring the ${ }^{31} \mathrm{P}$ transverse magnetization to the $z$-axis. For the measurements of HAp and brushite, the $t_{1}$ evolution is removed. 
HAp. The $\mathrm{OH}^{-}$groups in HAp form a linear chain parallel to the $c$-axis of the unit cell and the shortest $\mathrm{P}-\mathrm{H}$ distance is $3.847 \AA$ [38]. Brushite also has one phosphorus site $\left(\mathrm{HPO}_{4}^{2-}\right)$ and there are two structural water molecules per unit cell. The shortest $\mathrm{P}-\mathrm{H}$ distance is $2.189 \AA$ [39]. As a crude approximation, the build up of the DQ signals is described by a parabolic function [23]. By numerical simulations of multiple-spin systems, we have recently shown that the DQ signals will be attenuated by dephasing effects due to other passive spins [31]. Therefore, we chose to approximate the decay of the DQ signals by a Gaussian function for our multiple-spin systems [40]. Overall, the following empirical equation is used to fit the ${ }^{31} \mathrm{P}$ DQ signals as a function of excitation time:

$I\left(\tau_{\text {exe }}\right)=A \tau_{\text {exe }}^{2} \exp \left\{-\tau_{\text {exe }}^{2} / B\right\}$

where the rate of the initial DQ signal buildup is described by the parameter $A$, which is proportional to the $M_{2}^{P-P}$ value of the interacting nuclear spins; the constant $B$ describes the decay of the DQ signal. The excitation profiles of the DQ signals of HAp and brushite, which had been normalized with respect to the LG-CP MAS signals measured under similar conditions, were fitted by the above empirical equation in Fig. 4. Table 1 summarizes the extracted parameters $A$ and $B$ under different experimental conditions. Because the values of the parameter $B$ are affected both by the ${ }^{31} \mathrm{P}$ spin-spin relaxation time and the spatial arrangement of the interacting phosphorus species, it is difficult to interpret the data trend unequivocally and we will only focus on the parameter $A$ in the subsequent discussion. On the basis of the X-ray structures of HAp and brushite $[39,41]$, the corresponding $M_{2}^{P-P}$ values were calculated and hence the proportionality constants $M_{2}^{P-P} / A$.

As shown in Table 1 , the $M_{2}^{P-P} / A$ values determined at the spin rate of $25 \mathrm{kHz}$ are significantly smaller than those at $10 \mathrm{kHz}$. This observation can be rationalized by the fact that the undesirable effect of chemical shift anisotropy is suppressed under faster MAS because of the pulse symmetry of fp-RFDR [32]. At the spin rate of $25 \mathrm{kHz}$, the overall DQ excitation efficiency of HAp increases when the proton decoupling increases from 75 to $110 \mathrm{kHz}$ (Fig. 4). However, the converse is observed for brushite. We do not fully understand this counter-intuitive result of brushite. Nevertheless, the $M_{2}^{P-P} / A$ values determined at the two proton decoupling fields are quite similar for HAp or brushite. In summary, our results show that a direct comparison of the $A$ values determined for the phosphorous species in different environments, i.e. with different chemical shift anisotropies and/or proton decoupling efficacies, is not entirely meaningful. It is necessary to employ a suitable model compound to help extract the apparent $M_{2}^{P-P}$ of the studied system. Because the phosphorus species in the apatite component resemble closely to those in HAp [1], the $M_{2}^{P-P} / A$ data obtained for HAp will be used to estimate the $M_{2}^{P-P}$ values of the apatite component of the dentin sample. We also attempt to determine the apparent $M_{2}^{P-P}$ value of the amorphous component by brushite.

\subsection{DQF-HETCOR}

The HETCOR spectrum shown in Fig. 2 reveals that there are two different phosphorus species. This resolution enhancement is exploited to determine the ${ }^{31} \mathrm{P}-{ }^{31} \mathrm{P}$ second moments of the apatite and the amorphous components using the pulse sequence shown in Fig. 3. The idea is to add a DQ filter after the LG-CP HETCOR module so that the ${ }^{31} \mathrm{P}$ DQ signals of different phosphorus species can be differentiated. Fig. 5 shows the typical DQF-HETCOR spectrum measured for the dentin sample with the excitation time and the spin rate set equal to $2.56 \mathrm{~ms}$ and $25 \mathrm{kHz}$, respectively. The contributions from the apatite and the amorphous components to the ${ }^{31} \mathrm{P}$ DQ signal were obtained by integrating the highlighted region of the DQFHETCOR spectrum (Fig. 5). The efficiency of the DQ filter can then be obtained by normalizing the peak intensities with respect to the corresponding HETCOR signals measured under similar experimental conditions. A series of DQF-HETCOR spectra were measured at different excitation times to create the desired DQ excitation profile, which was then analyzed as described for HAp and brushite. For comparison, we also obtained the corresponding excitation profiles at the spin rate of $10 \mathrm{kHz}$, where a z-filter of $30 \mathrm{~ms}$ before the reading pulse was added to suppress any undesirable ${ }^{31} \mathrm{P}$ signals. Table 1 summarizes the parameters $A$ and $B$ determined for the apatite and the amorphous components of our dentin sample. Considering the apatite component, the apparent $M_{2}^{P-P}$ values determined at the spin rate of 25 and $10 \mathrm{kHz}$ are $(6.4 \pm 0.4)$ and $(6.8 \pm 0.5) \times 10^{6} \mathrm{rad}^{2} / \mathrm{s}^{2}$, respectively. This favorable agreement shows that the apparent $M_{2}^{P-P}$ value of the apatite component can be reliably obtained from the proportionality constant of HAp. The apparent $M_{2}^{P-P}$ value of the apatite component is smaller than that of HAp, which is consistent with the notion that some of the phosphate ions in biological apatites are substituted by carbonate ions [1]. On the other hand, the apparent $M_{2}^{P-P}$ values determined for the amorphous component at the spin rates of 25 and $10 \mathrm{kHz}$ differ considerably. The phosphorus species in the amorphous component of dentin may undergo the following proton exchange process:

$\mathrm{HPO}_{4}{ }^{2-}+\mathrm{OH}^{-}=\mathrm{H}_{2} \mathrm{O}+\mathrm{PO}_{4}^{3-}$.

Therefore, the phosphorus species in brushite and the amorphous component of dentin possibly have different behaviors with respect to DQ excitations. Although the apparent $M_{2}^{P-P}$ value of the amorphous component determined at $25 \mathrm{kHz}$ cannot be taken too literally, apparently the actual $M_{2}^{P-P}$ value of the amorphous component is less than that of HAp.

Finally, it is relatively straightforward to modify the current implementation of the DQF-HETCOR method. For example, one may remove the $t_{1}$ evolution from the 
$110 \mathrm{kHz}$
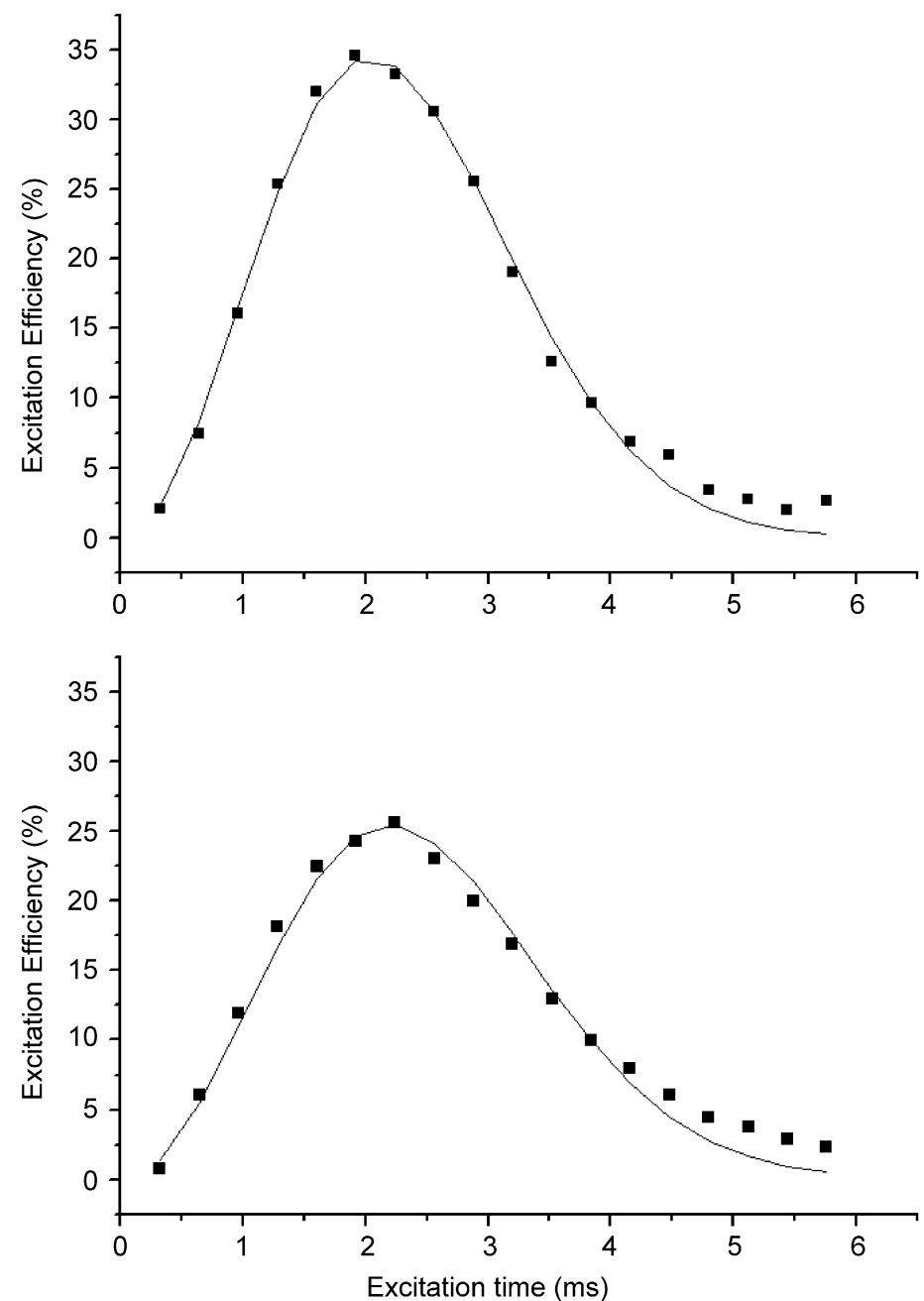

$75 \mathrm{kHz}$
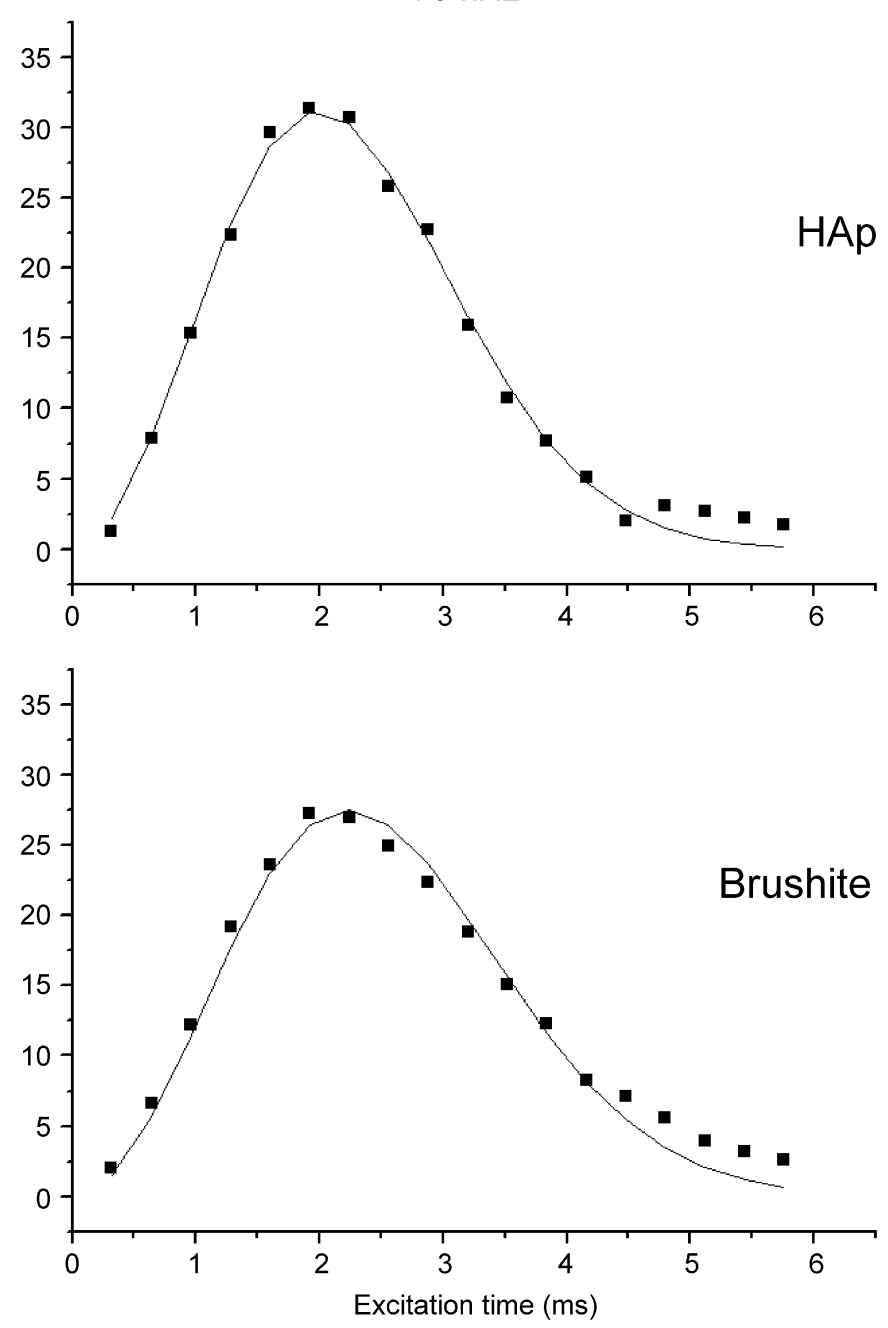

Fig. 4. Double-quantum excitation profiles obtained for HAp and brushite at the MAS frequency of $25 \mathrm{kHz}$. Proton decoupling fields were set to 75 and $110 \mathrm{kHz}$.

Table 1

Fitting parameters $A$ and $B$ of the ${ }^{31} \mathrm{P}$ homonuclear DQ excitation profiles and the apparent $M_{2}^{P-P}$ determined for the dentin sample

\begin{tabular}{|c|c|c|c|c|c|c|}
\hline & & & \multirow[t]{2}{*}{ HAp } & \multirow[t]{2}{*}{ Brushite } & \multicolumn{2}{|l|}{ Rat dentin } \\
\hline & & & & & $\begin{array}{l}\text { Apatite } \\
\text { component }\end{array}$ & $\begin{array}{l}\text { Amorphous } \\
\text { component }\end{array}$ \\
\hline$M_{2}^{P-P}\left(\times 10^{6} \mathrm{rad}^{2} / \mathrm{s}^{2}\right)$ & & & 7.70 & 6.27 & & \\
\hline Spin rate $25 \mathrm{kHz}$ & $\begin{array}{l}{ }^{1} \mathrm{H} \text { Decoupling } \\
75 \mathrm{kHz} \\
{ }^{1} \mathrm{H} \text { Decoupling } \\
{ }^{110 \mathrm{kHz}}\end{array}$ & $\begin{array}{l}A\left(\mathrm{~ms}^{-2}\right) \\
B\left(\mathrm{~ms}^{2}\right) \\
M_{2}^{P-P} / A \\
\text { Apparent } M_{2}^{P-P} \\
A \\
B \\
M_{2}^{P-P} / A\end{array}$ & $\begin{array}{l}21.4 \pm 0.6 \\
3.9 \pm 0.1 \\
0.36 \pm 0.01 \\
\\
22.4 \pm 0.6 \\
4.2 \pm 0.1 \\
0.34 \pm 0.01\end{array}$ & $\begin{array}{l}15.0 \pm 0.6 \\
5.0 \pm 0.1 \\
0.42 \pm 0.02 \\
\\
14.4 \pm 0.6 \\
4.8 \pm 0.1 \\
0.44 \pm 0.02\end{array}$ & $\begin{array}{l}17.9 \pm 0.5 \\
4.2 \pm 0.1 \\
6.4 \pm 0.4\end{array}$ & $\begin{array}{l}15.5 \pm 0.5 \\
4.5 \pm 0.1 \\
6.5 \pm 0.5\end{array}$ \\
\hline Spin rate $10 \mathrm{kHz}$ & $\begin{array}{l}{ }^{1} \mathrm{H} \text { Decoupling } \\
85 \mathrm{kHz}\end{array}$ & $\begin{array}{l}A \\
B \\
M_{2}^{P-P} / A \\
\text { Apparent } M_{2}^{P-P}\end{array}$ & $\begin{array}{l}10.6 \pm 0.5 \\
6.6 \pm 0.2 \\
0.73 \pm 0.03\end{array}$ & $\begin{array}{l}6.0 \pm 0.4 \\
8.4 \pm 0.4 \\
1.05 \pm 0.07\end{array}$ & $\begin{array}{l}9.3 \pm 0.2 \\
4.7 \pm 0.1 \\
6.8 \pm 0.5\end{array}$ & $\begin{array}{l}7.6 \pm 0.3 \\
5.3 \pm 0.1 \\
7.9 \pm 0.2\end{array}$ \\
\hline
\end{tabular}




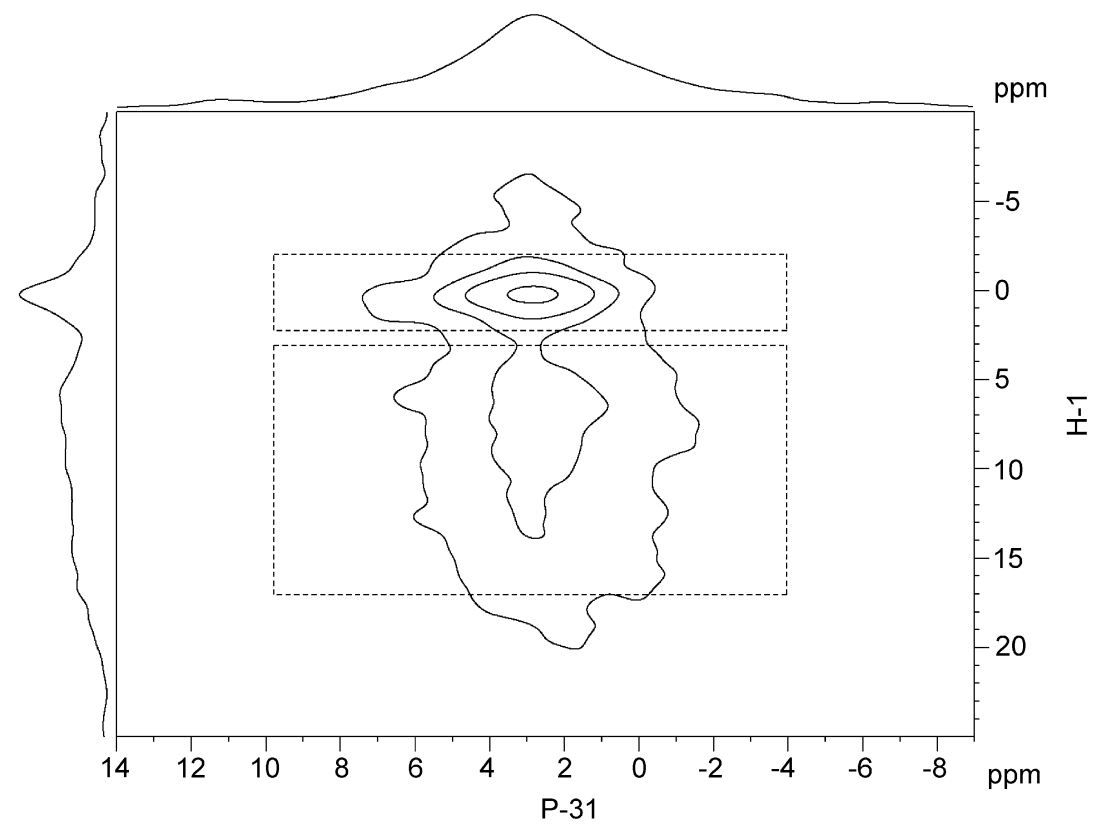

Fig. 5. DQF-HETCOR spectrum of the dentin sample measured at a spin rate of $25 \mathrm{kHz}$. The excitation and reconversion times were both set to $2.56 \mathrm{~ms}$. The contributions from the apatite and the amorphous components to the ${ }^{31} \mathrm{P} D Q$ signal were obtained by integrating the two rectangular regions centered at the ${ }^{1} \mathrm{H}$ chemical shifts of 0.2 and 9 ppm, respectively.

HETCOR module and insert it between the excitation and reconversion period, so that the resolution in the ${ }^{31} \mathrm{P}$ dimension could be exploited, if desired. The resolution in the ${ }^{1} \mathrm{H}$ dimension can be further enhanced by incorporating the so-called frequency-shift LG technique [10,42].

\section{Acknowledgments}

We thank the constructive comments from the anonymous reviewers. This work was supported by grants from the National Science Council.

\section{References}

[1] R.Z. LeGeros, Calcium Phosphates in Oral Biology and Medicine, Karger, Basel, 1991.

[2] W.P. Aue, A.H. Roufosse, M.J. Glimcher, R.G. Griffin, Biochemistry 23 (1984) 6110-6114.

[3] G.Y. Cho, Y.T. Wu, J.L. Ackerman, Science 300 (2003) 1123-1127.

[4] C. Jäger, N.S. Groom, E.A. Bowe, A. Horner, M.E. Davies, R.C. Murray, M.J. Duer, Chem. Mater. 17 (2005) 3059-3061.

[5] A. Kaflak, D. Chmielewski, A. Gorecki, A. Slosarczyk, W. Kolodziejski, Solid State Nucl. Magn. Reson. 29 (2006) 345-348.

[6] A. Kaflak-Hachulska, A. Samoson, W. Kolodziejski, Calcif. Tissue Int. 73 (2003) 476-486.

[7] A.H. Roufosse, W.P. Aue, J.E. Roberts, M.J. Glimcher, R.G. Griffin, Biochemistry 23 (1984) 6115-6120.

[8] Y. Wu, J.L. Ackerman, E.S. Strawich, C. Rey, H.M. Kim, M.J. Glimcher, Calcif. Tissue Int. 72 (2003) 610-626.

[9] Y.T. Wu, M.J. Glimcher, C. Rey, J.L. Ackerman, J. Mol. Biol. 244 (1994) 423-435.

[10] E.E. Wilson, A. Awonusi, M.D. Morris, D.H. Kohn, M.M.J. Tecklenburg, L.W. Beck, Biophys. J. 90 (2006) 3722-3731.

[11] R.A. Santos, R.A. Wind, C.E. Bronnimann, J. Magn. Reson. Ser. B 105 (1994) 183-187.
[12] W. Kolodziejski, Solid-state NMR studies of bone, in: J. Klinowski (Ed.), Topics in Current Chemistry, Vol. 246, Springer, Berlin, 2005, pp. 235-270.

[13] Y.T. Wu, J.L. Ackerman, H.M. Kim, C. Rey, A. Barroug, M.J. Glimcher, J. Bone Miner. Res. 17 (2002) 472-480.

[14] S. Dusold, A. Sebald, Dipolar recoupling under magic-angle spinning conditions, in: G.A. Webb (Ed.), Annual Reports on NMR Spectroscopy, Vol. 41, Academic Press, London, 2000, pp. 185-264.

[15] M. Baldus, Prog. Nucl. Magn. Reson. Spectrosc. 41 (2002) 1-47.

[16] I. Schnell, Prog. Nucl. Magn. Reson. Spectrosc. 45 (2004) 145-207.

[17] R. Tycko, Annu. Rev. Phys. Chem. 52 (2001) 575-606.

[18] I.J. King, F. Fayon, D. Massiot, R.K. Harris, J.S.O. Evans, Chem. Commun. (2001) 1766-1767.

[19] J. Schmedt auf der Günne, J. Magn. Reson. 165 (2003) 18-32.

[20] J. Schmedt auf der Günne, J. Magn. Reson. 18 (2006) 186-196.

[21] V. Raghunathan, J.M. Gibson, G. Goobes, J.M. Popham, E.A. Louie, P.S. Stayton, G.P. Drobny, J. Phys. Chem. B 110 (2006) 9324-9332.

[22] S. Olejniczak, P. Napora, J. Gajda, W. Ciesielski, M.J. Potrzebowski, Solid State Nucl. Magn. Reson. 30 (2006) 141-149.

[23] J. Schmedt auf der Günne, H. Eckert, Chem.-Eur. J. 4 (1998) $1762-1767$.

[24] K.S.K. Lin, Y.H. Tseng, Y. Mou, Y.C. Hsu, C.M. Yang, J.C.C. Chan, Chem. Mater. 17 (2005) 4493-4501.

[25] Y.-H. Tseng, C.-Y. Mou, J.C.C. Chan, J. Am. Chem. Soc. 128 (2006) 6909-6918.

[26] M. Lee, W.I. Goldburg, Phys. Rev. A 140 (1965) 1261.

[27] S. Hediger, B.H. Meier, R.R. Ernst, Chem. Phys. Lett. 240 (1995) 449-456.

[28] S. Hediger, B.H. Meier, N.D. Kurur, G. Bodenhausen, R.R. Ernst, Chem. Phys. Lett. 223 (1994) 283-288.

[29] Y. Ishii, J.J. Balbach, R. Tycko, Chem. Phys. 266 (2001) 231-236.

[30] N.A. Oyler, R. Tycko, J. Phys. Chem. B 106 (2002) 8382-8389.

[31] Y.H. Tseng, Y. Mou, C.Y. Mou, J.C.C. Chan, Solid State Nucl. Magn. Reson. 27 (2005) 266-270.

[32] Y. Ishii, J. Chem. Phys. 114 (2001) 8473-8483.

[33] T. Gullion, D.B. Baker, M.S. Conradi, J. Magn. Reson. 89 (1990) 479-484. 
[34] R.R. Ernst, G. Bodenhausen, A. Wokaun, Principles of Nuclear Magnetic Resonance in One and Two Dimensions, Clarendon Press, Oxford, 1987.

[35] D.I. Hoult, R.E. Richards, Proc. R. Soc. London Ser. A-Math. Phys. Eng. Sci. 344 (1975) 311-340.

[36] J.P. Yesinowski, H. Eckert, J. Am. Chem. Soc. 109 (1987) 6274-6282.

[37] C. Jäger, T. Welzel, W. Meyer-Zaika, M. Epple, Magn. Reson. Chem. 44 (2006) 573-580.
[38] K. Sudarsanan, R.A. Young, Acta Crystallogr. B 25 (1969) 1534-1543.

[39] N.A. Curry, D.W. Jones, J. Chem. Soc. A (1971) 3725.

[40] M. Engelsberg, R.E. Norberg, Phys. Rev. B 5 (1972) 3395.

[41] M.I. Kay, R.A. Young, A.S. Posner, Nature (London) 204 (1964) 1050-1052.

[42] A. Bielecki, A.C. Kolbert, H.J.M. de Groot, R.G. Griffin, M.H. Levitt, Adv. Magn. Reson. 14 (1990) 111-124. 